\title{
Compatibility and kidney transplantation: the way to go
}

\section{Ilias I. N. Doxiadis*}

Eurotransplant Reference Laboratory, Department of Immunohaematology and Blood Transfusion, Leiden University Medical Center, Leiden, Netherlands

\section{Edited by:}

Rene Duquesnoy, University of

Pittsburgh Medical Center, USA

\section{Reviewed by:}

Ann-Margaret Little, NHS Greater Glasgow and Clyde, Scotland

Thomas Eiermann, University hospital

Hamburg-Eppendorf, Germany

\section{*Correspondence:}

llias I. N. Doxiadis, Eurotransplant

Reference Laboratory, Department of Immunohaematology and Blood

Transfusion, Leiden University

Medical Center, Albinusdreef 2, 2333

ZA Leiden, Netherlands.

e-mail: doxiadis@lumc.n!
Long lasting debates in the past questioned the relevance of any sort of compatibility in post mortal kidney transplantation. It is for no say that fully compatible transplants have the highest chances for a long patient and graft survival. In the present report the use of HLA-DR as a representative of the Major Histocompatibility Complex class II genes in the allocation of organs is discussed. The major arguments are the easiness to offer to patients a compatible graft in a relatively short waiting time, an increase in graft survival, the less sensitization during the transplantation period, and the lower waiting time for a retransplant. Even if the number of organ donors remains the same a lowering of the mean waiting time is expected because of the longer period of graft survival.

Keywords: kidney transplantation, HLA-DR, matching, compatibility

\section{INTRODUCTION}

The role of HLA compatibility as a parameter for allocation of kidneys from deceased donors to patients on the kidney waiting list remains a matter of debate. It is well accepted that the best possible organ for an end stage renal disease patient is a fully HLA compatible kidney. The arguments of those acting against compatibility do not follow scientific criteria. Both graft and patient survival in post mortal kidney transplantation are significantly better in compatible groups compared to kidneys transplanted with incompatibilities (Doxiadis et al., 2004; Kaneku and Terasaki, 2006; Opelz and Döhler, 2007; Johnson et al., 2010). The same holds true for kidneys from living donors (Opelz, 1997). Furthermore, HLA incompatible organs are the source of HLA antigens toward which the patient can, even under immunosuppressive therapy, form alloantibodies. Following the rules of Immunology this step is triggered by the patients own HLA system. These alloantibodies are currently suggested to be the main cause of graft destruction (Sijpkens et al., 1999). Furthermore, incompatibilities render the patient (highly) sensitized and after primary graft loss more difficult to be offered a suitable donor kidney for retransplantation. Alloantibodies have been related not only to acute but especially to chronic allograft dysfunction, better discussed as chronic rejection. Intervening therapies are used to treat patients with alloantibodies such as intravenous immunoglobulines (Glotz et al., 1993; Gebel and Halloran, 2010), anti-CD20 monoclonal antibodies recognizing the $\mathrm{B}$ cells and proteasome inhibitors as Bortezomib (Trivedi et al., 2010). The results are not always satisfactory. Prevention of alloantibody formation would be a good alternative to the unsatisfactory treatment, which in the case of transplantation results often into secondary problems like degenerative diseases such as cancer (Opelz and Döhler, 2010).

\section{HLA-DR COMPATIBILITY}

Many mostly European organ exchange organizations allocate kidneys on the basis of HLA matching by giving more points to better matched patients than those with a lower matching degree (Doxiadis et al., 2004; Johnson et al., 2010). A selection of a specific locus, e.g., HLA-DR, is not yet the rule. Earlier it has been shown that HLA-DR compatibility leads to an increased graft survival for patients receiving a primary graft. The effect of HLAA, B compatibility disappears when patients receive a HLA-DR incompatible organ (Doxiadis et al., 2007). These results have been obtained using a large number of transplant $(N=35,205)$ in the transplantation period of 1985-2005. In a follow-up study retransplants were analyzed (Doxiadis et al., 2010). For the same period as shown above post mortem kidney retransplants were selected. The recipients were $\geq 18$ years old while the donors were over 5 years old. Transplants performed via special Eurotransplant programs were excluded. End point of this analysis was graft loss censored for death with functioning graft. Kaplan-Meier product limit method was used to estimate survival rates. For the estimation of relative risks (hazard ratios) for different variables Cox proportional hazard regression was used. Adjusted survival curves were plotted using the same procedure. All analyses were performed with the SPSS statistical package, version 14 (SPSS Inc., Chicago, IL, USA). The course of post transplantation follow-up was analyzed in the three separate phases post transplantation: initial ( $<1$ year), intermediate ( $\geq 1$ to $<5$ years), and late phase ( $\geq 5$ years follow-up).

The results of these analyses are similar to the ones obtained for the primary transplants. The effect of HLA-A, B compatibility exists as expected over time and mimics the results already shown for primary transplants. By introducing an HLA-DR incompatibility the effect of HLA-A, B compatibility disappears (Doxiadis et al., 2010).

The risk factors in multivariate analysis showed that donor age already reported for the primary grafting and also in many other studies and sensitization degree of the patient at transplantation are deleterious for the patient. Finally, HLA-A, B incompatibility is an independent factor resulting in a higher graft loss in the 
first phase ( $\leq 1$ year) post transplantation, presumably because of alloantibodies or unreported earlier sensitization of the patients.

These results are based on a seroequivalent HLA-DR typing (DR1-DR18) or a molecular typing of the first field, according to the new nomenclature. In a simulation study we could show that even on a local basis it is possible to offer to almost all patients on the waiting list a fully HLA-DR compatible organ even including patients of different genetic background, allowing an equitable allocation to all patients on the waiting list.

The production of alloantibodies toward incompatibilities of the donor is related to the MHC class II compatibility. In case patients receive incompatible HLA-DR organs they have a significantly higher chance to produce alloantibodies against the donor than in the case of compatible grafts (Doxiadis et al., 2007). Many studies have been reported since the seminal publication of Terasaki (2003) regarding the production of alloantibodies toward the graft and its relation to transplantation. If one admits that these alloantibodies affect allograft survival then prevention of their formation might be the answer since selective elimination is impossible to date.

The alloantibody prevention scenario for future transplant might look as follows:

As a first step patients are offered a fully HLA-DR (DRB1) compatible graft. Epitopes leading to alloantibody formation should be avoided, e.g., Bw4 in HLA-DR1 or DR3 recipients (Fuller and Fuller, 1999). After this initial phase full compatibility also for other than HLA-DRB1 specificities should be aimed. At present no conclusive data for any effect of HLA-DRB3,4,5 in large registries are available, the same holds true for HLA-DQ. The very strong associations between most of the HLA-DRB1 alleles to HLA-DQ specificities make this type of analyses difficult and require large data sets, which are currently not available. The HLA phenotype of the patient will lead to the selection of organs with a low chance of alloantibody formation. The patients should be closely monitored with respect to alloantibody production, e.g., monthly at the initial phase of up to 6 months, and then at intervals of about 6 months, for two reasons: first, for possible treatment and second for data collection in order to fully understand alloantibody formation under transplantation circumstances. The final step in this scenario would be to offer every patient a graft with the least chances for HLA alloantibody formation (Duquesnoy et al., 2003).

\section{REFERENCES}

Doxiadis, I. I., de Fijter, J. W., Mallat, M. J., Haasnoot, G. W., Ringers, J., Persijn, G. G., and Claas, F. H. (2007). Simpler and equitable allocation of kidneys from postmortem donors primarily based on full HLADR compatibility. Transplantation 83, 1207-1213.

Doxiadis, I. I., Smits, J. M., Persijn, G. G., Frei, U., and Claas, F. H. (2004). It takes six to boogie: allocating cadaver kidneys in Eurotransplant. Transplantation 77, 615-617.

Doxiadis, I. I., Rahmel, A., and Claas, F. H. (2010). Towards kidney allocation on basis of HLA-DR

The proposed scenario would offer the following benefits:

1. Increased graft and patient survival.

2. A significant decrease of the sensitization toward donor HLA incompatibilities during the transplantation period and, in case of organ loss, more, and better possibilities for retransplantation.

3. Decrease of waiting time for the retransplant.

4. Reduced incidence of side effects, normally associated with the additional immunosuppressive regiments necessary to treat rejection episodes.

This proposal is only the first step needed to reduce allosensitization of patients receiving a kidney allograft. It is our intention to introduce on the long term additional steps such as compatibility of epitopes leading to alloantibodies. It is essential to reproduce the data mentioned at the beginning of this review using local or regional transplantation outcome, since controversial results have been reported (e.g., Gritsch et al., 2008).

\section{CONCLUSION}

All patients should receive a fully HLA-DR compatible graft, resulting in an increased graft survival and reduced allosensitization.

\section{SUMMARY}

"Until immunosuppressive regiments are directed toward the humoral component of graft rejection simple prevention should be aimed in the field of post mortal kidney transplantation." Alloantibodies are not only a relevant factor before transplantation but are also a cause of allograft dysfunction after transplantation. Full compatibility for MHC class II together with intelligent introduction of incompatibilities could be seen as a first step in a series of possibilities to diminish allosensitization without the need of additional immunosuppressive treatments.

\section{AUTHOR NOTE}

In kidney transplantation it is important to note that by eliminating the one component of the immune system other components can take over. Until now the T cells were quoted as the "bad" guys. In the present period B cells took over. Recently, we showed that NK cells (van Bergen et al., 2011) are associated with graft loss in the later period of transplantation (Gritsch et al., 2008). The future will show what we should do.

the responder. Transplantation 68 , 173-183.

Gebel, H. M., and Halloran, P. F (2010). Making sense of desensitization. Am. J. Transplant. 10, 443-444.

Glotz, D., Haymann, J. P., Sansonetti, N., Francois, A., Menoyo-Calonge, V., Bariety, J., and Druet, P. (1993). Suppression of HLA-specific alloantibodies by high-dose intravenous immunoglobulins (IVIg). A potential tool for transplantation of immunized patients. Transplantation 56, 335-337.

Gritsch, H. A., Veale, J. L., Leichtman, A. B., Guidinger, M. K., Magee, J.
C., McDonald, R. A., Harmon, W. E., Delmonico, F. L., Ettenger, R. B., and Cecka, J. M. (2008). Should pediatric patients wait for HLA-DR-matched renal tansplants? Am. J. Transplant. 8, 2056-2061.

Johnson, R. J., Fuggle, S. V., O’Neill, J., Start, S., Bradley, J. A., Forsythe, J. L., and Rudge, C. J. (2010). Kidney Advisory Group of NHS Blood and Transplant Factors influencing outcome after deceased heart beating donor kidney transplantation in the United Kingdom: an evidence base for a new national kidney allocation policy. Transplantation 89, 379-386. 
Kaneku, H. K., and Terasaki, P. I. (2006). Thirty year trend in kidney transplants: UCLA and UNOS Renal Transplant Registry. Clin. Transpl. 1-27.

Opelz, G. (1997). Impact of HLA compatibility on survival of kidney transplants from unrelated live donors. Transplantation 64, 1473-1475.

Opelz, G., and Döhler, B. (2007). Effect of human leukocyte antigen compatibility on kidney graft survival: comparative analysis of two decades. Transplantation 84, 137-143.

Opelz, G., and Döhler, B. (2010). Impact of HLA mismatching on incidence of posttransplant nonHodgkin lymphoma after kidney transplantation. Transplantation 89, 567-572.

Sijpkens, Y. W., Doxiadis, I. I., De Fijter, J. W., Mallat, M. J., van Es, L. A., De Lange, P., Zwinderman, A. H., Westendorp, R. G., van Kemenade, F. J., Bruijn, J. A., Claas, F. H., and Paul, L. C. (1999). Sharing cross-reactive groups of MHC class I improves long-term graft survival. Kidney Int. 56, 1920-1927.

Terasaki, P. I. (2003). Humoral theory of transplantation. Am. J. Transplant. 3, 665-673.

Trivedi, H. L., Terasaki, P. I., Feroz, A., Vanikar, A. V., Trivedi, V. B., Khemchandani, S. I., Dave, S. D., Shankar, V., Modi, P. R., Kaneku, H., Idica, A., and Everly, M. J. (2010). Clonal deletion with bortezomib followed by low or no maintenance immunosuppression in renal allograft recipients. Transplantation 90, 221-222.

van Bergen, J., Thompson, A., Haasnoot, G. W., Roodnat, J. I., de Fijter, J. W., Claas, F. H., Koning, F., and Doxiadis, I. I. (2011). KIR-ligand mismatches are associated with reduced long-term graft survival in HLAcompatible kidney transplantation. Am. J. Transplant. 11, 1959-1964.

Conflict of Interest Statement: The author declares that the research was conducted in the absence of any commercial or financial relationships that could be construed as a potential conflict of interest.
Received: 01 July 2011; paper pending published: 26 August 2011; accepted: 19 April 2012; published online: 14 May 2012.

Citation: Doxiadis IIN (2012) Compatibility and kidney transplantation: the way to go. Front. Immun. 3:111. doi: 10.3389/fimmu.2012.00111

This article was submitted to Frontiers in Alloimmunity and Transplantation, a specialty of Frontiers in Immunology.

Copyright (C) 2012 Doxiadis. This is an open-access article distributed under the terms of the Creative Commons Attribution Non Commercial License, which permits non-commercial use, distribution, and reproduction in other forums, provided the original authors and source are credited. 